Cahiers $d u$ MONDE RUSSE

\section{Cahiers du monde russe}

Russie - Empire russe - Union soviétique et États indépendants

$50 / 4 \mid 2009$

Varia

\title{
Oksana S. Nagornaja, Drugoj voennyj opyt
}

\section{Alexandre Sumpf}

\section{OpenEdition \\ Journals}

Édition électronique

URL : https://journals.openedition.org/monderusse/7162

DOI : 10.4000/monderusse. 7162

ISSN : $1777-5388$

\section{Éditeur}

Éditions de l'EHESS

\section{Édition imprimée}

Date de publication : 15 décembre 2009

Pagination : 801-803

ISBN : 978-2-7132-2261-0

ISSN : $1252-6576$

\section{Référence électronique}

Alexandre Sumpf, «Oksana S. Nagornaja, Drugoj voennyj opyt », Cahiers du monde russe [En ligne], 50/4 | 2009, mis en ligne le 12 janvier 2011, consulté le 03 septembre 2022. URL : http://

journals.openedition.org/monderusse/7162; DOI : https://doi.org/10.4000/monderusse.7162

Ce document a été généré automatiquement le 3 septembre 2022.

Tous droits réservés 


\title{
Oksana S. Nagornaja, Drugoj voennyj opyt
}

\author{
Alexandre Sumpf
}

\section{RÉFÉRENCE}

Oksana S. NAGORNAJA, Drugoj voennyj opyt. Rossijskie voennoplennye Pervoj

mirovoy vojny v Germanii (1914-1922) [Une autre expérience de guerre : Les

prisonniers de guerre russes de la Première Guerre mondiale en Allemagne (1914-1922)].

Moscou : Novyj Hronograf, 2010, 440 p.

1 Tiré d'une thèse (kandidatskaja dissertacija) rédigée sous la tutelle de I. Narskij, le présent ouvrage traite de manière convaincante du sort des 1,5 million de soldats russes capturés par l'armée allemande au cours de la Première Guerre mondiale. L'approximation des chiffres correspond au nombre élevé des "disparus » (propavšie bez vesti) qui singularise l'expérience russe et fait que ni les autorités allemandes, ni l'état-major russe, ni les instances chargées du rapatriement (Centroplenbež), ni la Commission spéciale d'enquête sur les conséquences de la guerre «impérialiste» ne sont parvenus à déterminer la quantité des morts, prisonniers, blessés et invalides.

2 Le principal mérite d'Oksana Nagornaja est d'avoir utilisé des sources russes et allemandes, centrales et locales, institutionnelles et personnelles, articulées la plupart du temps avec bonheur, bien que fasse parfois défaut une mise en perspective dans le contexte russe et international. L'auteur propose aussi une chronologie rigoureuse de cette expérience singulière, jusqu'au rapatriement des derniers détenus, en 1922, au moment où l'URSS sort victorieuse de la guerre civile et commence à gagner sa place dans le concert des nations.

3 La première partie inscrit le sort des prisonniers dans le débat tant international que national. Ce sort fait l'objet d'une intense publicité en Russie - au service de la propagande anti-allemande et de la lutte contre la désertion - comme en Allemagne, où l'on vante au contraire le respect des conventions internationales. Mais les prisonniers 
reçoivent une faible assistance de la part des autorités russes, alors que les mauvais traitements semblent être la règle. Un soupçon de lâcheté et de traîtrise pèse même sur ceux qui parviennent à s'enfuir ; tous ceux qui reviennent sont longuement interrogés, par plusieurs instances. Ce n'est qu'à partir du printemps 1915 que « l'interdiction semiofficielle» (p. 58) de s'occuper des Russes détenus est levée. Des organisations civiles (zemstva, municipalités, associations charitables, unions) établissent des listes pour les familles, récoltent des fonds pour envoyer aliments, vêtements, etc., visitent les camps. On s'interroge sur les facteurs de la prééminence de certaines régions sur d'autres en ce domaine, ou de Moscou sur Petrograd: sans doute cela relève-t-il des traditions de bienfaisance, d'éducation populaire et des capacités économiques, ainsi que des conséquences de l'accueil ou du rejet des réfugiés.

4 La deuxième partie traite des conditions d'internement, évoluant de l'improvisation totale (avec un taux de décès en conséquence) à l'organisation puis à la différenciation des camps selon l'origine des détenus (rang, nationalité, religion) et la destination (transit, soin, travaux forcés) à partir de la seconde moitié de 1915. Les Allemands (davantage que les Autrichiens, à la tête de leur propre mosaïque ethnique) ont en effet opéré une différenciation raciste, axée sur la proximité ethnico-linguistique (Allemands de la Volga, Baltes, voire juifs) et les (contradictoires) nationalismes polonais et ukrainien. Le principal résultat de cette politique de privilèges a été la volonté de s'identifier comme non russe, dans le cadre d'une stratégie de survie (individuelle) plus que d'une prise de conscience nationaliste (collective).

5 Dans plus d'une centaine de camps varient ainsi conditions alimentaires, vestimentaires et psychologiques : mise en condition des gardiens, mépris du soldat abandonné par son gouvernement, conceptions racistes du commandant. Les mauvais traitements réservés aux Russes sont avérés. Plus que la mortalité de ces prisonniers, quasi équivalente à celle des autres nations, c'est la fréquence de la tuberculose qui révèle, outre une mauvaise santé initiale, sous-alimentation et insalubrité de l'hébergement. La situation est pire encore pour les mobilisés dans les brigades de travail, hors contrôle militaire ou civil, notamment dans les mines et l'industrie; mais meilleure dans l'agriculture, où jouent la proximité de condition entre employeurs et employés, l'accès à la nourriture et l'émergence (parfois tactique) d'idylles avec de jeunes Allemandes.

6 La troisième partie, plus courte, tente une sociologie des camps, faite de hiérarchies superposées et de solidarités opposées : certaines professions (artisans, médecins) sont privilégiées, certains types sont soupçonnés de collaborer (juifs), les groupes de pays (zemljačestva) pratiquent l'entraide, les comités privilégient le rapport aux autorités et à la société russe pour le rapatriement et la préparation du retour dans la nouvelle Russie... La barrière de la langue gêne les Russes dans la compréhension de leurs compagnons étrangers, les clichés xénophobes réglant en général les rapports internationaux au camp. L'image du " pouvoir absolu » (p. 121) du commandant aurait gagné à être nuancée par une réflexion sur les interactions entre collectifs (comités, administration) et individus (prisonniers, gardes, autorités). Les différences entre camps relèvent de la personnalité du commandant autant que de la situation géographique, dans une Allemagne très marquée par les différences régionales - ici familière du monde slave, là plus religieuse, ailleurs encore rétive à l'effort de guerre, etc.

7 La section suivante, tirant le parti des nouvelles tendances historiographiques, s'intéresse à la perception de l'expérience par les prisonniers à travers leur langage et leurs comportements, façonnés par l'adaptation au chaos initial pour les uns, à un 
système de valeurs strict pour ceux qui arrivent à partir de 1916. Les spécificités de la culture de guerre russe - faible apport à la langue russe (pas d'argot identifiable) ou aux pratiques de communication (inexistence des journaux de tranchées), expérience de la censure - auraient mérité une comparaison avec les pratiques des autres nations. Les Russes semblent avoir davantage tenté de fuir que les Français ou les Britanniques et, à défaut de participer aux révolutions de 1917, ont joué un rôle (local) dans celle de novembre 1918 en Allemagne: serait-ce dû aux conditions de détention, à une politisation après Février 1917 ? Les passages sur le jargon de camp, sur une religiosité empreinte de morale entraînant une forme d'intolérance envers toute religion non orthodoxe après Octobre, ou sur la formation professionnelle ne permettent pas de trancher entre radicalisation et utilisation $d u$ vocabulaire et des attitudes révolutionnaires afin de rentrer au plus tôt.

8 La dernière partie lance la réflexion sur le retour à la vie civile des prisonniers de la Grande Guerre, certains cohabitant dans les camps avec les soldats de l'Armée rouge capturés en Ukraine. Les soldats du tsar, même réengagés du côté bolchevik, reprennent rarement le combat et servent plutôt dans les unités de maintien de l'ordre: ils ne paraissent pas «brutalisés». D'autres choisissent les Blancs, quelques-uns restent en Allemagne, surtout s'ils n'ont aucune attache particulière au pays. Dans l'ensemble, l'expérience spécifique liée à la guerre « impérialiste » se dissout dans le tumulte de la guerre civile. Si ce retour offre au pouvoir soviétique un précieux apprentissage de la négociation internationale ou de la gestion des flux de population, on peut douter que les anciens combattants parviennent à valoriser leur expérience de guerre et même à perpétuer le souvenir de leur sacrifice. 